\title{
Molecular Imprinted of Nylon 6 for Selective Separation of Procaine by Solid-Phase Extraction
}

\author{
Muhammed Emad Abood and Sumayha Muhammed Abbas \\ Department of Chemistry, College of Education for Pure Science Ibn Al-Haitham, University of Baghdad, Baghdad, Iraq
}

*Corresponding author:

tel: $+9641-7700876525$

email:

sumayha.m.a@ihcoedu.uobaghdad.edu.iq

Received: June 24, 2021

Accepted: August 16, 2021

DOI: $10.22146 /$ ijc. 66997

\begin{abstract}
The study is based on the selective binding ability of the drug compound procaine (PRO) on a surface imprinted with nylon 6 (N6) polymer. Physical characterization of the polymer template was performed by X-ray diffraction and DSC thermal analysis. The imprinted polymer showed a high adsorption capacity to trap procaine $(237 \mu \mathrm{g} / \mathrm{g})$ and excellent recognition ability with an imprinted factor equal to 3.2. The method was applied to an extraction column simulating a solid-phase extraction to separate the drug compound in the presence of tinoxicam and nucleosimide separately and in a mixture of them with a recovery rate more than the presence of tinoxicam and nucleosimide separately and in a mixture of them with a recovery rate of more than $82 \%$. Separation efficiency and excellent selectivity for procaine were ensured using a mixed solution injected into an HPLC technique consisting of a C18 column with a mobile phase mixture of water-acetonitrile (75:25) at $\mathrm{pH}$ 3.3. The study of drug control using an imprinted polymer with procaine compound showed that the complete drug release process is faster at pH1 in a maximum period of $80 \mathrm{~min}$. The proposed method was successfully applied on some of the available pharmaceuticals, and it showed high selectivity for the separation of PRO, $R E \%$ was $<1.18$, and RSD was less than 0.447 .
\end{abstract}

Keywords: imprinting polymer; nylon 6; phase inversion method; solid-phase extraction; procaine

\section{- INTRODUCTION}

Procaine [2-(diethylamino) ethyl4-aminobenzoate) (Fig. 1) is considered a powerful aesthetic with antiinflammatory properties [1]. The main purpose of the drug is to minimize intramuscular injection pain of penicillin and dentistry. As the trade name in several countries, novocaine is the generic name referring to procaine. Its main performance is to block the sodium channels. Because of its anti-inflammatory, moodimproving, sympatholytic, and perfusion-enhancing effects, it was used for therapeutic reasons in some regions. PRO was prepared in 1905 for the first time afterward, amylocaine. PRO is used for spinal anesthesia, therapeutic, and local infiltration blockade [2].

Imprinted polymer technique is used to create cavities or molecular fingerprints with high selectivity for the analyte and using polymers for this purpose called molecularly imprinted polymers. These cavities can be specially designed according to different requirements, thus demonstrating a high selectivity towards imprinted particles. Moreover, the advantages of the MIP technique are low cost, easy to synthesize, chemical and physical stability, and re-use ability. Identification cavities defined in an artificial polymer are referred to as molecularly imprinted polymer (MIP). Recognition of MIP mostly mimics biological routes that have been employed in many fields [3], such as biological [4-6] and chemical detecting [7-10], quantitative detection [1113], extraction, and purification [14-16]. Nylon 6 is biocompatible, mechanically, and thermally stable. It has been used in various sensors, the most important of which is in DNA sensor chips. The preparation method of molecularly imprinted nylon 6 is achieved by a phase inversion method from the liquid phase to the solid phase. 
<smiles>CCN(CC)CCOC(=O)c1ccc(N)cc1</smiles>

Fig 1. Chemical structure of procaine

There are many suitable solvents for polyamide, including formic acid, hydrochloric acid, and acetic acid. The polymer structure is characterized by being porous and having very great importance [17]. The procaine component is an amino ester local anesthetic acting on the fast sodium channel to produce local anesthesia. This anesthetic addition intends primarily to ease the pain of IM injection in large enough doses to reach therapeutic concentrations. Therefore it will be combined with other drugs that the patient takes it. We choose tinoxicam and nucleosimide as a matrix with procaine. This study includes using nylon 6 as a suitable polymer for establishing the molecular imprinting of procaine based on its phase inversion to the purpose of the selective separation and extraction of procaine in its pure form and its pharmaceuticals.

\section{- EXPERIMENTAL SECTION}

\section{Materials}

Pure form (99.99\%) pharmaceutical grade procaine powder was obtained as a gift from State Corporation for Drug Industries and Medical Appliances Samara/Iraq (SDI). The chemicals and reagents used are of analytical grade. The solutions used in this study were prepared as the following: the stock solution of each procaine $\left(100 \mu \mathrm{g} \mathrm{mL}^{-1}\right)$, tinoxicam (SDI), and niclosemide (SEGMA) drugs were prepared by weighing $0.01 \mathrm{~g}$ of the drug and dissolving it in a $100 \mathrm{~mL}$ volumetric flack filled with distilled water. $\mathrm{K}_{2} \mathrm{HPO}_{4}(0.5 \mathrm{M})$ solution prepared by dissolving $43.60 \mathrm{~g}$ in a $500 \mathrm{~mL}$ volumetric flask. $\mathrm{Na}_{2} \mathrm{HPO}_{4}$ $(0.5 \mathrm{M})$ solution was set by dissolving $35.80 \mathrm{~g}$ in a $500 \mathrm{~mL}$ volumetric flask. $\mathrm{KH}_{2} \mathrm{PO}_{4}(0.2 \mathrm{M})$ solution was prepared by dissolving $13.60 \mathrm{~g}$ in a $500 \mathrm{~mL}$ volumetric flask. $\mathrm{NaOH}$ $(0.1 \mathrm{M})$ solution was acquired by dissolving $0.40 \mathrm{~g}$ in a $100 \mathrm{~mL}$ volumetric flask of distilled water. Buffer solution $(\mathrm{pH} 1)$ to simulate gastric fluids was prepared by adding $0.83 \mathrm{~mL}$ of $\mathrm{HCl}$ to a $50 \mathrm{~mL}$ volumetric flask and then completing the volume was completed to the mark with distilled water while monitoring the $\mathrm{pH}$. Buffer solution of $\mathrm{pH} 6.8$ was prepared to simulate intestinal fluids by mixing $25.5 \mathrm{~mL}$ of $\mathrm{K}_{2} \mathrm{HPO}_{4}(0.5 \mathrm{M})$ with $25.5 \mathrm{~mL}$ of $\mathrm{Na}_{2} \mathrm{HPO}_{4}(0.5 \mathrm{M})$ solution with continuous stirring by a magnetic stirrer, while monitoring the $\mathrm{pH}$ with a $\mathrm{pH}$ meter [18]. Buffer solution ( $\mathrm{pH}$ 7.4) simulated blood plasma was prepared by mixing $250 \mathrm{~mL}$ of $\mathrm{KH}_{2} \mathrm{PO}_{4}$ at a concentration of $0.2 \mathrm{M}$ with $393.4 \mathrm{~mL}$ of $0.1 \mathrm{M} \mathrm{NaOH}$, with continuous stirring by a magnetic stirrer, while monitoring the $\mathrm{pH}$ with a $\mathrm{pH}$ meter [18].

\section{Instrumentation}

All spectroscopic measurements were performed, and absorption spectra were recorded on a Shimadzu UV-Vis dual-beam spectrophotometer with an identical $1 \mathrm{~cm}$ quartz cell. HPLC KNAUER Wissenschaftliche Geräte GmbH, Germany, Ultra-Sonic devise, Germany - SONOREX and XRD spectroscopy Shimadzu 6000, Japan, Differential scanning calorimetry (DSC) of samples were performed by DSC-60 system Shimadzu company-Japan.

\section{Procedure}

\section{Determine the maximum wavelength and calibration curve for procaine}

The maximal absorption of PRO was determined using the UV-Vis spectrophotometric method, which involved pouring $1 \mathrm{~mL}$ of PRO from a $100 \mu \mathrm{g} \mathrm{mL}^{-1}$ stock solution into a $10 \mathrm{~mL}$ volumetric flask and filling the flask with distilled water. Against the blank, the final solution shows a maximum absorption at $290 \mathrm{~nm}$. Solutions of different drug concentrations were prepared to study the calibration curve by taking different volumes of the drug ranging from $0.1-1.4 \mathrm{~mL}$ and placing them in $10 \mathrm{~mL}$ volumetric flask, then completing the volume with distilled water to the mark.

\section{Preparation of molecularly imprinted polymer (MIP)}

Two chemicals, $1.6 \mathrm{~g}$ of $\mathrm{N} 6$ and $0.02 \mathrm{~g}$ for PRO, were weighed separately and mixed well, dissolved in 20 $\mathrm{mL}$ of formic acid to prepare MIP (molecularly imprinted polymer) against NIP (non-imprinted polymer) that was prepared with the same procedure but without PRO. After that, the mixture was agitated at 
room temperature for $5 \mathrm{~min}$ to achieve complete dissolution. The mixture was then placed into $200 \mathrm{~mL}$ of cold distilled water to solidify the polymer. After phase inversion, the imprinted polymer was washed with distilled water to eliminate the drug compound and leave its imprint on the polymer surface. The washing was done in an ultrasonic bath with $250 \mathrm{~mL}$ of distilled water for $15 \mathrm{~min}$. Next, the polymer was filtered and rinsed with $50 \mathrm{~mL}$ of distilled water several times. Then, the MIP polymer was allowed to dry at room temperature, after which it was ground and stored. $1.53 \mathrm{~g}$ of PRO/N6-MIP was obtained. Finally, for non-imprinted polymer (NIP), all of the previous steps was repeated, but without the PRO drug.

\section{Pharmaceutical preparation}

Devapen Injection, DEVA, Turkey ( $800 \mathrm{mg} / 2 \mathrm{~mL})$. The extraction sample was prepared by mixing the contents of 10 vials of powder of the injection, then weighing $0.01 \mathrm{~g}$ from the mixture and dissolving it in a $100 \mathrm{~mL}$ volumetric flask with distilled water to obtain $100 \mu \mathrm{g} \mathrm{mL}{ }^{-1}$ stock solution. Then $0.7,1.0$, and $1.3 \mathrm{~mL}$ was drawn from the stock solution and placed in $10 \mathrm{~mL}$ volumetric flask. The volume was completed with distilled water. The extraction process was duplicated three times under the same conditions.

\section{Separation column design}

A $20 \mathrm{~mL}$ glass syringe $(150 \mathrm{~mm} \times 20 \mathrm{~mm})$ with a mechanical press was used as a column. First, a double layer of filter paper (WIN LAB, Germany, and $150 \mathrm{~mm}$ ) was placed inside the syringe, and then $0.5 \mathrm{~g}$ of MIP and NIP were separately inserted into the column for the initial study. After that, the mechanical press was assembled as well.

\section{The initial approach of solid-phase extraction by MIP}

A $0.5 \mathrm{~g}$ for each PRO/N6 MIP and NIP were weighed and placed in separation columns activated with $10 \mathrm{~mL}$ of distilled water in five batches. First, $10 \mathrm{~mL}$ of a $10 \mathrm{~g} \mathrm{~mL}^{-1}$ drug solution was put into the column and permitted to equilibrate for $5 \mathrm{~min}$ before being mechanically pressed. Next, the solution extracted from the column was collected in a $10 \mathrm{~mL}$ volumetric flask, and the absorption was measured for those solutions with a UV-Vis spectrophotometer at $290 \mathrm{~nm}$ and room temperature for PRO. The binding capacity was estimated by the following equation [19]:

$\mathrm{Q}=\frac{\left(\mathrm{C}_{0}-\mathrm{C}_{\mathrm{e}}\right) \times \mathrm{V}}{\mathrm{W}}$

$\mathrm{Q}(\mu \mathrm{g} / \mathrm{g})$ is referred to the holding capacity for the MIP, $\mathrm{C}_{0}(\mu \mathrm{g} / \mathrm{mL})$ was the primary concentration, $\mathrm{V}$ referred to the primary sample solution volume, $C_{e}(\mu \mathrm{g} / \mathrm{mL})$ referred to the sample solution equilibrium concentration, W (g) referred to the MIP quantity in gram.

The dissociation constant $K_{d}$ was estimated by the following equation [19]:

$\frac{\mathrm{Q}}{\mathrm{C}_{\mathrm{e}}}=\frac{\mathrm{Q}_{\max -\mathrm{Q}}}{\mathrm{K}_{\mathrm{d}}}$

$\mathrm{Q}$ is the holding capacity, $\mathrm{C}_{\mathrm{e}}$ refers to the sample solution equilibrium concentration, $\mathrm{Q}_{\max }$ refers to the extreme holding capacity, and $\mathrm{K}_{\mathrm{d}}$ is the division constant correlated with adsorption site attraction.

The calculation of the Imprinting factor IF was done by the fraction of $\mathrm{Q}_{\max }-\mathrm{MIP}$ to the $\mathrm{Q}_{\max }-\mathrm{NIP}$ and then utilized to evaluate non-specific and specific interactions [19]:

$\mathrm{IF}=\frac{\mathrm{Q}_{\max }(\mathrm{MIP})}{\mathrm{Q}_{\max }(\mathrm{NIP})}$

Finally, the calculation of an accumulative rate of release (\%) was done by the following relation [20]:

Accumulation release rate $(\%)=\frac{\mathrm{M}_{\mathrm{t}}}{\mathrm{M}_{\infty}} \times 100 \%$

$M_{t}$ is the increasing quantity of the drug at a specific time. $M_{\infty}$ referred to the increasing quantity of the drug at an endless time.

\section{Binding performance assessment}

In this study, the optimal circumstances for the separation process were evaluated. Furthermore, the factors affecting the efficiency of the binding capacity, such as the quantity of MIP, the optimum temperature, and the equilibrium duration, were also studied.

\section{Scatter plot study of PRO}

Different drug solutions were separately prepared with concentrations ranging from $2-13 \mu \mathrm{g} \mathrm{mL}^{-1}$ by transferring $0.2-1.3 \mathrm{~mL}$ from a $100 \mu \mathrm{g} \mathrm{mL}^{-1}$ stock 
solution by placing them in a $10 \mathrm{~mL}$ volumetric flask and completing the volume with distilled water. After that, the extraction process was performed with MIP and NIP at optimum temperature and equilibrium time, and then the absorption of the extracted solution was measured at $290 \mathrm{~nm}$ for PRO.

\section{- RESULTS AND DISCUSSION}

\section{The Absorption Spectra and Calibration Curve}

The maximum wavelength of $10 \mu \mathrm{g} \mathrm{mL} \mathrm{L}^{-1} \mathrm{PRO}$ was determined by a UV-Vis spectrophotometric. Fig. (2-3) shows different concentrations of the drug with the absorption spectrum and linear range that obey beers law.

\section{Characterization of Imprinting Polymer}

\section{XRD identification}

Fig. 4 presents the X-ray diffraction (XRD) structure of NIP and MIP with procaine. The X-ray spectrum reveals the three strongest crystalline peaks at 2-theta of $24.38^{\circ}, 20.41^{\circ}$, and $12.13^{\circ}$. The intensity of each peak increased, indicating that the crystalline increased because the pharmaceutical particle became a source of nucleation, resulting in greater crystal growth [21].

\section{DSC analysis}

The sample was examined by weighing $25 \mathrm{mg}$ of the sample and increasing the temperature at a $10^{\circ} \mathrm{C} / \mathrm{min}$ rate. As illustrated in Fig. 5, DSC analysis for NIP shows the endothermic point at $199{ }^{\circ} \mathrm{C}$ which is related to the melting point. The peak at $178.71{ }^{\circ} \mathrm{C}$ shows the process of thermal recrystallization. On the other hand, the figure shows that the melting point value of MIP did not change much from NIP, appeared at $199.35^{\circ} \mathrm{C}$, while the peak of recrystallization showed a clear difference and appeared close to $163.21{ }^{\circ} \mathrm{C}$.

\section{Elementary Study of Solid-Phase Extraction by PRO/N6-MIP}

The first solid phase extraction attempt by each of the MIP and NIP was done using the separation column to $10 \mathrm{~mL}$ solution of the drug of $10 \mu \mathrm{g} \mathrm{mL}^{-1}$ concentration with an equilibrium time of $5 \mathrm{~min}$. Following results illustrated in Table 1 indicated a large variance in $Q$ value amongst imprinted MIP and non-imprinted polymer
NIP, which confirms the effectiveness of templet formation.

\section{The Effect of PRO/N6-MIP Weight Study}

Different weights were taken from the MIP, ranging from $(0.1-0.7) \mathrm{g}$, and the extraction process was

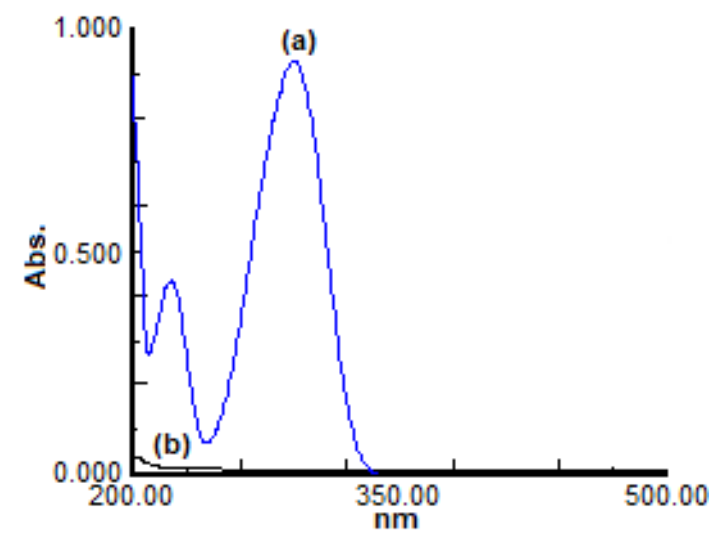

Fig 2. (a) Absorption spectrum of $10 \mu \mathrm{g} \mathrm{mL}^{-1}$ of $P R O$ with maximum absorption band at $290 \mathrm{~nm}$, (b) Blank solution

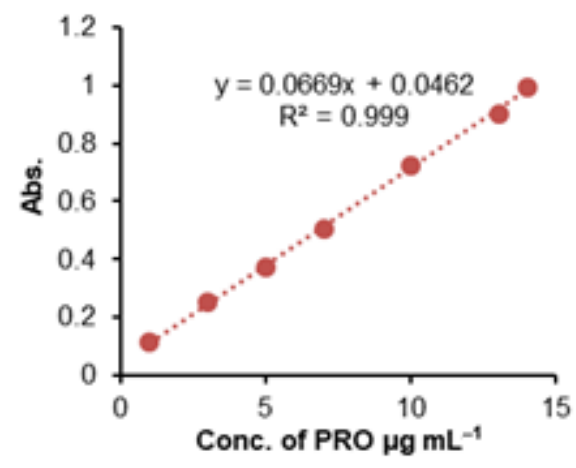

Fig 3. Calibration curve of procaine

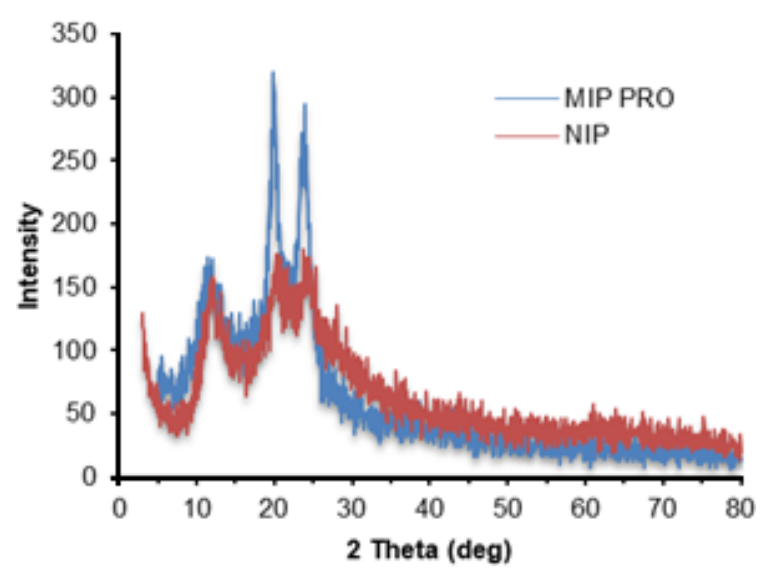

Fig 4. X-ray $(\mathrm{Cu} \mathrm{Ka} \lambda=1.54060 \mathrm{~A})$ diffraction of NIP and PRO/N6-MIP 


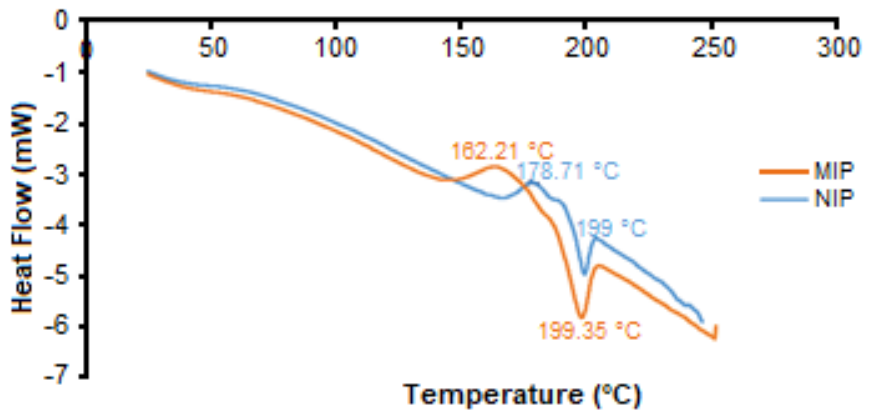

Fig 5. DSC analysis for NIP and PRO/N6-MIP

Table 1. Adsorption capacity related to NIP, MIP, for a $10 \mu \mathrm{g} \mathrm{mL} \mathrm{m}^{-1} \mathrm{PRO}$

\begin{tabular}{lccc}
\hline Sample & Abs & $\mathrm{Ce}\left(\mu \mathrm{g} \mathrm{mL}^{-1}\right)$ & $\mathrm{Q}\left(\mu \mathrm{g} \mathrm{g}^{-1}\right)$ \\
\hline MIP & 0.510 & 6.9 & 62.0 \\
NIP & 0.700 & 9.77 & 4.6 \\
STOCK & 0.725 & 10.00 & - \\
\hline
\end{tabular}

executed under the same circumstances. Table 2 showed that the weight of $0.5 \mathrm{~g}$ of MIP gives the best binding capacity at $67.20 \mu \mathrm{g} \mathrm{g}^{-1}$. Q remains constant in the higher weights, and the reason was the selective holes in PRO/N6-MIP being saturated with PRO [22]. So it has been established in the next study.

\section{The Effect of Solution Temperature}

Different drug samples were prepared with the same concentration and applied with MIP and NIP to evaluate the effect of temperature on the separation process. Fig. 6 showed that the temperature of $70{ }^{\circ} \mathrm{C}$ gives the best binding capacity value equal to $136.80 \mu \mathrm{g} \mathrm{g}^{-1}$ compared to $69 \mathrm{mg} \mathrm{g}^{-1}$ for the NIP. The changes of $\mathrm{Q}$ with temperature are due to many reasons, such as modification of hole size, hydrophobic interaction, hydrogen bonding interaction [23-25]. There is a strong inclination that the pore size in the polymer is amplified with the increase in temperature. Thus, pore size is an essential reason for the rise in binding capacity with increased temperature, which enables the approximation of PRO molecules to the specific holes. [26].

\section{The Effect of Equilibrium Time Study}

The extraction process was performed with different equilibrium times for the drug solution under the optimum conditions. Results showed in Fig. 7 illustrated that the best holding capacity, $199.10 \mu \mathrm{g} \mathrm{g}^{-1}$, was obtained at $40 \mathrm{~min}$, which was applied in subsequent studies.

The dynamic adsorption curves of the NIP, MIP were recognized through observing procaine concentration over 1-60 min. As shown in Fig. 8, the Q value of MIP improved rapidly after $5 \mathrm{~min}$ and reached

Table 2. The effect of PRO/N6-MIP weight on the binding capacity

\begin{tabular}{lccc}
\hline Sample $(\mathrm{g})$ & $\mathrm{Abs}$ & $\mathrm{Ce}\left(\mu \mathrm{g} \mathrm{mL}^{-1}\right)$ & $\mathrm{Q}\left(\mu \mathrm{g} \mathrm{g}^{-1}\right)$ \\
\hline 0.10 & 0.650 & 9.02 & 19.60 \\
0.20 & 0.631 & 8.74 & 25.20 \\
0.30 & 0.617 & 8.53 & 29.40 \\
0.50 & 0.491 & 6.64 & 67.20 \\
0.60 & 0.491 & 6.64 & 67.20 \\
0.70 & 0.491 & 6.64 & 67.20 \\
\hline
\end{tabular}

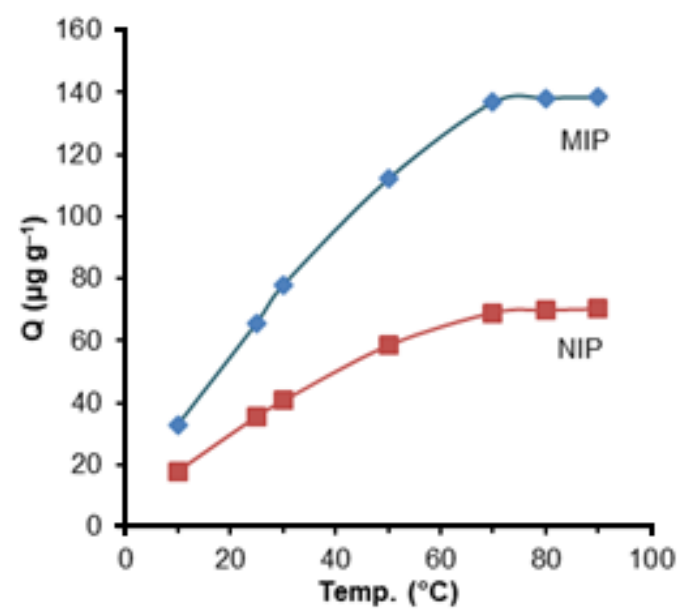

Fig 6. Isotherm curves of PRO/N6-MIP, NIP

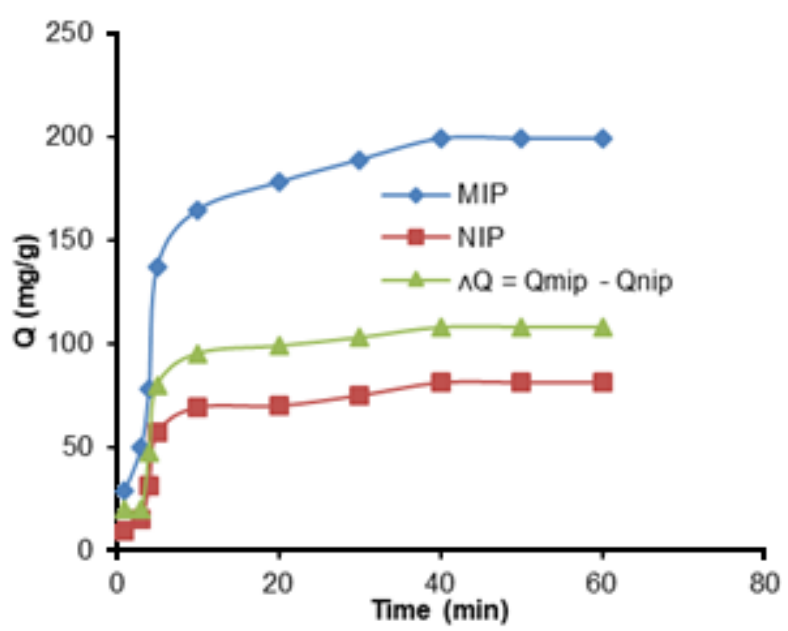

Fig 7. Dynamic curves of adsorption for the PRO/N6MIP, NIP toward PRO 

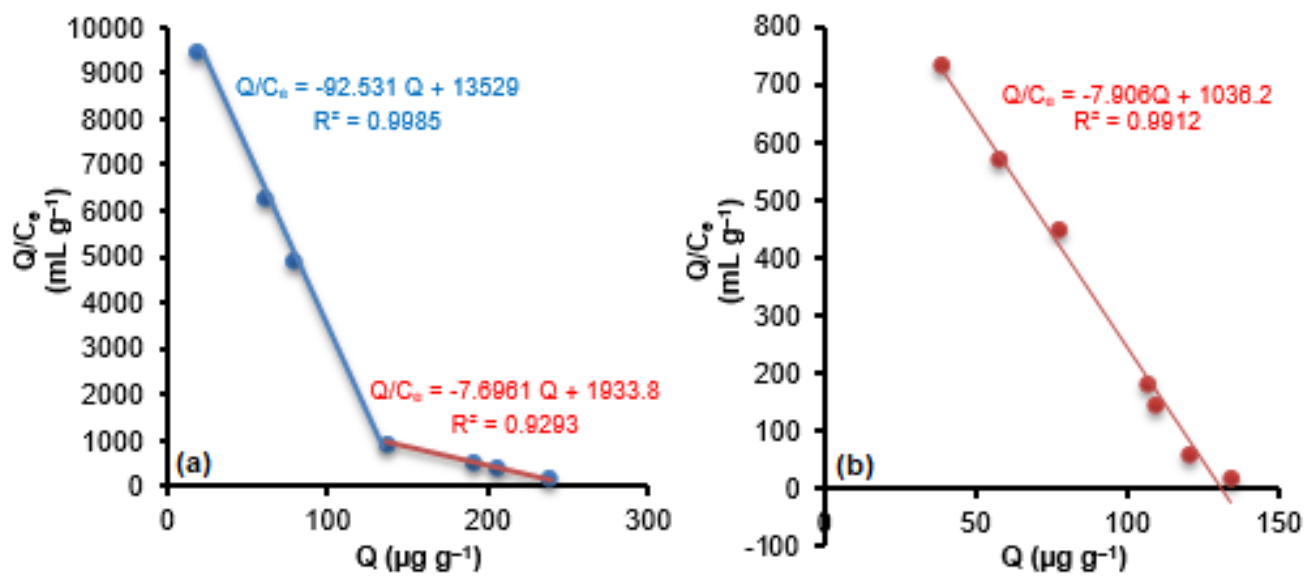

Fig 8. Scatter plot study of the (a) PRO/N6-MIP, (b) NIP

its optimum equilibrium time at $40 \mathrm{~min}$. After $40 \mathrm{~min}$, the $Q$ value was nearly unaffected, suggesting that MIP selective holes were saturated by procaine adsorption and stabilized. The specific adsorption Q amplified through time, signifying the procaine imprinting efficiency. Results exposed that MIP could be utilized as a transporter for the separation and adsorption of procaine [20], and this was acceptable when compared with that obtained by Surikumaran et al. [27].

\section{PRO/N6-MIP Scatter Plot Study}

Different drug solutions were prepared as mentioned in the experimental part, and the extraction process was performed with MIP and NIP at the temperature of $70{ }^{\circ} \mathrm{C}$, and an equilibrium time of 40 minutes. The results showed in Fig. 8(a, b) for MIP and NIP, respectively.

Scatter plots were an additional examination of the adsorption capacity, which was useful for assessing adsorption positions. The Scatter plot (Fig. 8(a)) for MIP exhibited two lines, the first positions with low affinity and the other representing high-affinity positions, suggesting that there were two different kinds of adsorption spots (superficial positions besides cavities) in the MIP. While the plot for NIP (Fig. 8(b)) showed the same line of surface site in MIP (have the same slop), this result is consistent with $\mathrm{Ma}$ et al. [19]. The positions of low affinity showed a dissociation constant that was similar to that of the non-imprinted polymer but greater than that of the positions of high-affinity Table 3 . The positions of low affinity showed an IF, $\mathrm{Q}_{\max }$ that was superior to that of the positions of high affinity. The least $\mathrm{Q}_{\max }$ was to that of the NIP. Thus, the results proposed that positions of low affinity existed on the surface of the MIP and the positions of high affinity situated in the cavities of the imprinted polymer. The non-imprinted N6 had only positions that were non-selective and on the surface only [19].

\section{The Selectivity of PRO/N6-MIP}

Two different solutions were prepared by mixing $10 \mu \mathrm{g} \mathrm{mL}{ }^{-1}$ of procaine with $10 \mu \mathrm{g} \mathrm{m}^{-1}$ for each niclosemide and tinoxicam separately in a $10 \mathrm{~mL}$ volume flask. Then the extraction process was performed to separate procaine in the presence of the two different matrices (niclosemide and tinoxicam). PRO/N6-MIP showed very good selectivity for PRO with $85 \%$ recovery compared with the NIP as shown in Table 4.

\section{Extraction Efficiency Estimation of PRO/N6-MIP}

The selectivity of PRO-MIP by HPLC technique was studied, using a C18 column, the mobile phase was

Table 3. Maximum binding capacity $\left(\mathrm{Q}_{\max }\right)$ and imprinting factor (IF) acquired by the Scatter plot for procaine

\begin{tabular}{lccc}
\hline Polymer & $\mathrm{K}_{\mathrm{d}}$ & $\mathrm{Q}_{\max }$ & $\mathrm{IF}$ \\
\hline MIP-high & 0.058 & 191 & 1.42 \\
MIP-low & 0.137 & 237 & 1.76 \\
NIP & 0.147 & 134 & - \\
\hline
\end{tabular}


Table 4. Selective adsorption of the PRO/N6-MIP to PRO in the presence of niclosemide and tinoxicam

\begin{tabular}{lcccccccc}
\hline \multirow{2}{*}{ Matrix } & \multicolumn{4}{c}{$\mathrm{MIP}$} & \multicolumn{4}{c}{$\mathrm{NIP}$} \\
\cline { 2 - 10 } & $\mathrm{Abs}$ & $\mathrm{C}_{\mathrm{e}}\left(\mu \mathrm{g} \mathrm{mL}^{-1}\right)$ & $\mathrm{Q}\left(\mu \mathrm{gg}^{-1}\right)$ & $\operatorname{Rec}(\%)^{*}$ & $\mathrm{Abs}$ & $\mathrm{C}_{\mathrm{e}}\left(\mu \mathrm{g} \mathrm{mL}^{-1}\right)$ & $\mathrm{Q}\left(\mu \mathrm{g} \mathrm{g}^{-1}\right)$ & $\operatorname{Rec}(\%)^{*}$ \\
\hline Niclosemide & 0.078 & 0.47 & 190.6 & 85.0 & 0.350 & 4.5 & 110 & 44 \\
Tinoxicam & 0.086 & 0.59 & 188.2 & 82.6 & 0.374 & 4.8 & 104 & 45 \\
\hline
\end{tabular}

water-acetonitrile $(75: 25)$ modified to $\mathrm{pH} 3.3$ by glacial acetic acid at $40{ }^{\circ} \mathrm{C}$, the sample was prepared by mixing equal quantities of PRO with both tenoxicam and Niclosemide. Fig. 9 showed a significant decrease in the peak height of PRO extracted from PRO-MIP compared to NIP and the mixture (PRO, CLP, and TNX) without the extraction process.

\section{Drug Release Study of PRO/N (6)-MIP}

Three solutions were prepared with different $\mathrm{pH}$ values: $1,6.8$, and 7.4 simulating to gastric, intestinal, and blood plasma fluids, respectively. After that, MIP performed the extraction process of a $10 \mu \mathrm{g} \mathrm{mL}^{-1}$ solution of the drug. In this process, the MIP polymer was transferred from the extraction column and placing in $100 \mathrm{~mL}$ buffer solutions, and the absorption at different periods was measured and plotted in Fig. 10.

The measured release of PRO/N6-MIP was conceded under stirring at $25{ }^{\circ} \mathrm{C}$. The results specified that the accumulative release rate of $\mathrm{PRO}$ was $\mathrm{pH}$ dependant. The release rate in the acidic buffer was remarkably faster than that of $\mathrm{pH} 6.8$ and $\mathrm{pH} 7.4$ because procaine is a weak organic base. Thus it dissolved in the stomach fluid effortlessly, leading to a breakdown of imprinted N6. On the other hand, the imprinted N6 presented an excellent capability of $\mathrm{PRO}$ release control at $\mathrm{pH} 7.4$ and 6.8. This result is attributed to the selective binding positions present in the polymer matrix that gradually releases PRO. Therefore, imprinted N6 could be exploited by way of possible unique substance to the purpose of organized discharge, allowing the delivery of procaine to a fixed position in the clinical uses [28].

\section{Application of the Proposed Method on Pharmaceuticals}

Pharmaceuticals in the form of Devapen injections had been used, and the proposed method was applied to these injections. Different volumes of pharmaceutical solutions were taken with a final volume of $10 \mathrm{~mL}$. The extraction process was performed with MIP and NIP under the same conditions. Table 5 showed that PRO/N6-MIP gives a high selectivity for PRO extraction from pharmaceuticals compared with NIP.

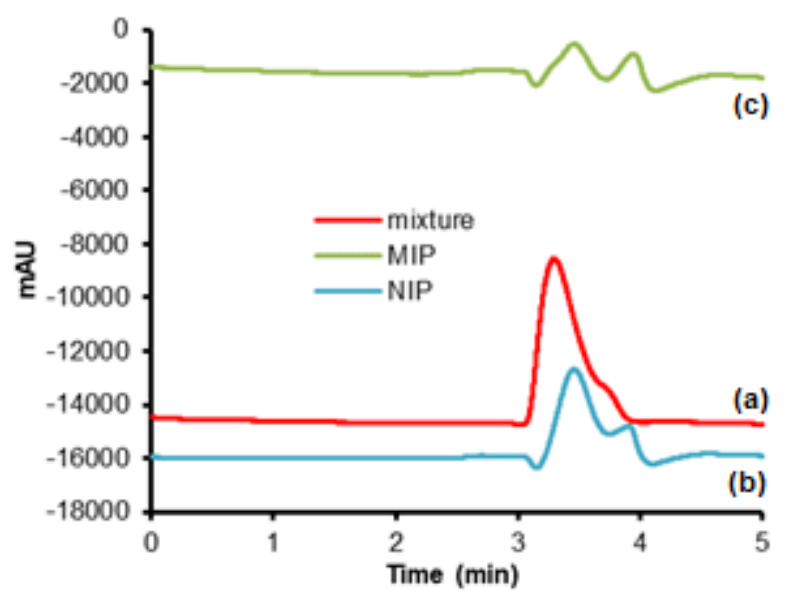

Fig 9. HPLC chromatogram of (a) Mixture of $10 \mu \mathrm{g} \mathrm{mL}$ of each PRO, tenoxicam, and niclosemide, (b) The mixture after extraction with NIP, and (c) The mixture after extraction with PRO/N6-MIP

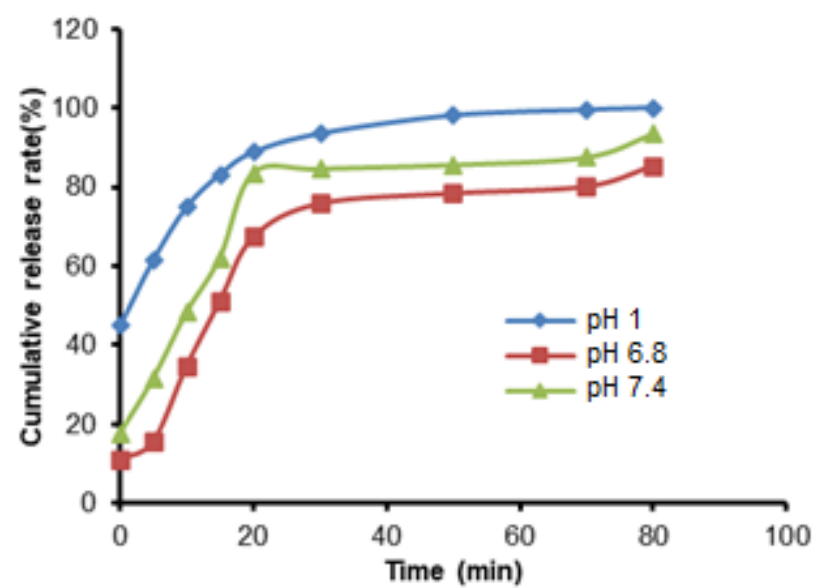

Fig 10. Control curves of PRO/N6-MIP in the various $\mathrm{pH}$ solutions 
Table 5. Application of the proposed method to the separation of PRO in dosage form

\begin{tabular}{|c|c|c|c|c|c|c|c|c|c|c|}
\hline \multirow[b]{2}{*}{$\begin{array}{l}\text { Pharma. } \\
\text { Preparation }\end{array}$} & \multirow{2}{*}{$\begin{array}{c}\text { Labeled } \\
\text { amount } \\
(\mathrm{mg})\end{array}$} & \multirow{2}{*}{$\begin{array}{c}\text { Conc. } \\
\text { taken } \\
\left(\mu \mathrm{g} \mathrm{mL} L^{-1}\right)\end{array}$} & \multicolumn{4}{|c|}{ MIP } & \multicolumn{4}{|c|}{ NIP } \\
\hline & & & $\begin{array}{c}\mathrm{C}_{\mathrm{e}} \\
\left(\mu \mathrm{g} \mathrm{mL}^{-1}\right)^{\star}\end{array}$ & $\begin{array}{c}Q \\
\left(\mu \mathrm{g} \mathrm{g}^{-1}\right)\end{array}$ & $\begin{array}{l}\mathrm{RE} \\
(\%)\end{array}$ & $\begin{array}{c}\text { RSD } \\
\%\end{array}$ & $\begin{array}{c}\mathrm{Ce} \\
\left(\mu \mathrm{g} \mathrm{mL}^{-1}\right)^{*}\end{array}$ & $\begin{array}{c}Q \\
\left(\mu \mathrm{g} \mathrm{g}^{-1}\right)\end{array}$ & $\begin{array}{l}\mathrm{RE} \\
(\%)\end{array}$ & $\begin{array}{l}\text { RSD } \\
(\%)\end{array}$ \\
\hline \multirow{3}{*}{$\begin{array}{l}\text { Devapen } \\
\text { injection/Turkey }\end{array}$} & \multirow{3}{*}{800} & 7 & 0.148 & 137.38 & 0.218 & 0.026 & 3.433 & 71.34 & -47.957 & 0.991 \\
\hline & & 10 & 0475 & 190.78 & -0.313 & 0.747 & 4.556 & 108.88 & -43.181 & 0.846 \\
\hline & & 13 & 1.010 & 239.80 & 1.180 & 0.004 & 5.452 & 150.96 & -36.303 & 0.951 \\
\hline
\end{tabular}

${ }^{\star}$ Each measurement is repeated three times

\section{- CONCLUSION}

In this study, the polymer nylon 6 was molecularly imprinted with procaine by a phase inversion method. The molecular imprinting polymer was applied to separate the drug compound successfully by using the SPE technique. The study showed the importance of experimental conditions for efficient separation, extraction, and obtaining the highest binding capacity value. The separation efficiency was monitored using the HPLC technique, were showed good selectivity for the drug compound in the presence of tinoxicam and nucleosemide. The study showed the possibility of efficiently using the imprinted polymer to study the controlled release of procaine in different acidic media. The proposed method was successful in separating PRO in its pure form and in pharmaceuticals.

\section{- REFERENCES}

[1] Fleckenstein, J., König, M., and Banzer, W., 2018, Neural therapy of an athlete's chronic plantar fasciitis: A case report and review of the literature, $J$. Med. Case Rep., 12 (1), 233.

[2] Plotycya, S., Strontsitska, O., Pysarevska, S., Blazheyevskiy, M., and Dubenska, L., 2018, A new approach for the determination of benzocaine and procaine in pharmaceuticals by single-sweep polarography, Int. J. Electrochem., 2018, 1376231.

[3] Lu, L., Yue, X., Lin, F., Huang, F., Zhang, B., and Lin, Z., 2015, Template-synthesized ultra-thin molecularly imprinted polymers membrane for the selective preconcentration of dyes, J. Mater. Chem. A, 3 (20), 10959-10968.

[4] Xu, X., Chen, X., Yang, L., Zhao, Y., Zhang, X., Shen, R., Sun, D., and Qian, J., 2020, Film-like bacterial cellulose-based molecularly imprinted materials for highly efficient recognition and adsorption of cresol isomers, Chem. Eng. J., 382, 123007.

[5] Bereli, N., Akgönüllü, S., Asliyüce, S., Çimen, D., Göktürk, İ., Türkmen, D., Yavuz, H., and Denizli, A., 2020, Molecular imprinting technology for biomimetic assemblies, Hacettepe J. Biol. Chem., 48 (5), 575-601.

[6] Li, D.W., Zhai, W.L., Li, Y.T., and Long, Y.T., 2014, Recent progress in surface-enhanced Raman spectroscopy for the detection of environmental pollutants, Microchim. Acta, 181 (1), 23-43.

[7] Chen, L., Wang, X., Lu, W., Wu, X., and Li, J., 2016, Molecular imprinting: Perspectives and applications, Chem. Soc. Rev., 45 (8), 2137-2211.

[8] Herrera-Chacón, A., Cetó, X., and del Valle, M., 2021, Molecularly imprinted polymers-towards electrochemical sensors and electronic tongues, Anal. Bioanal. Chem., 413 (24), 6117-6140.

[9] Saylan, Y., Yilmaz, F., Özgür, E., Derazshamshir, A., Yavuz, H., and Denizli, A., 2017, Molecular imprinting of macromolecules for sensor applications, Sensors, 17 (4), 898.

[10] Yang, Q., Li, J., Wang, X., Peng, H., Xiong, H., and Chen, L., 2018, Strategies of molecular imprintingbased fluorescence sensors for chemical and biological analysis, Biosens. Bioelectron., 112, 54-71.

[11] Zhang, Y., Wang, H.Y., He, X.W., Li, W.Y., and Zhang, Y.K., 2021, Homochiral fluorescence responsive molecularly imprinted polymer: Highly chiral enantiomer resolution and quantitative detection of L-penicillamine, J. Hazard. Mater., $412,125249$.

[12] Ashley, J., Wu, K., Hansen, M.F., Schmidt, M.S., Boisen, A., and Sun, Y., 2017, Quantitative detection of trace-level cloxacillin in food samples using 
magnetic molecularly imprinted polymer extraction and surface-enhanced Raman spectroscopy nanopillars, Anal. Chem., 89 (21), 11484-11490.

[13] Zhao, X., Cui, Y., He, Y., Wang, S., and Wang, J., 2020, Synthesis of multi-mode quantum dots encoded molecularly imprinted polymers microspheres and application in quantitative detection for dopamine, Sens. Actuators, B, 304, 127265.

[14] Wang, C., Hu, X., Guan, P., Wu, D., Qian, L., Li, J., and Song, R., 2015, Separation and purification of thymopentin with molecular imprinting membrane by solid-phase extraction disks, J. Pharm. Biomed. Anal., 102, 137-143.

[15] Yang, Z., Wang, J., Shah, T., Liu, P., Ahmad, M., Zhang, Q., and Zhang, B., 2021, Development of surface imprinted heterogeneous nitrogen-doped magnetic carbon nanotubes as promising materials for protein separation and purification, Talanta, 224, 121760.

[16] Shi, W., Zhang, S.Q., Li, K.B., Jia, W.P., and Han, D.M., 2018, Integration of mixed-mode chromatography and molecular imprinting technology for double recognition and selective separation of proteins, Sep. Purif. Technol., 202, 165173.

[17] Dmitrienko, E.V., Bulushev, R.D., Haupt, K., Kosolobov, S.S., Latyshev, A.V., Pyshnaya, I.A., and Pyshnyi, D.V., 2013, A simple approach to prepare molecularly imprinted polymers from nylon-6, $J$. Mol. Recognit., 26 (8), 368-375.

[18] Vogel, A.I., Mendham, J., Denney, R.C., Barnes, J.D., and Thomas, M.J.K., 2000, Vogel's Textbook of Quantitative Chemical Analysis, $6^{\text {th }}$ Ed., Prentice Hall, Harlow, UK.

[19] Ma, X., Lin, H., Zhang, J., Zhou, X., Han, J., She, Y., Qiu, C., He, Q., Wang, J., and Rabah, T., 2018, Preparation and characterization of dummy molecularly imprinted polymers for separation and determination of farrerol from Rhododendron aganniphum using HPLC, Green Chem. Lett. Rev., 11 (4), 513-522.
[20] Zhang, W., She, X., Wang, L., Fan, H., Zhou, Q., Huang, X., and Tang, J.Z., 2017, Preparation, characterization and application of a molecularly imprinted polymer for selective recognition of sulpiride, Materials, 10 (5), 475.

[21] Meenan, P.A., Anderson, S.R., and Klug, D.L., 2002, "The Influence of Impurities and Solvents on Crystallization" in Handbook of Industrial Crystallization, $2^{\text {nd }}$ Ed., Eds. Myerson, A.S., Butterworth-Heinemann, Oxford, UK, 67-100.

[22] Olcer, Y.A., Demirkurt, M., Demir, M.M., and Eroglu, A.E., 2017, Development of molecularly imprinted polymers (MIPs) as solid-phase extraction (SPE) sorbent for the determination of ibuprofen in water, RSC Adv., 7 (50), 31441-31447.

[23] Saeed, A., Sharif, M., and Iqbal, M., 2010 Application potential of grapefruit peel as dye sorbent: Kinetics, equilibrium, and mechanism of crystal violet adsorption, J. Hazard. Mater., 179 (13), 564-572.

[24] Zabihi, M., Asl, A.H., and Ahmadpour, A., 2010, Studies on adsorption of mercury from aqueous solution on activated carbons prepared from walnut shell, J. Hazard. Mater., 174 (1-3), 251-256.

[25] Komiyama, M., Takeuchi, T., Mukawa, T., and Asanuma, H., 2003, Molecular Imprinting: From Fundamentals to Applications, Wiley-VCH Verlag $\mathrm{GmbH} \& \mathrm{Co}$. KGaA, Weinheim.

[26] Tao, Y., Dai, J., Kong, Y., and Sha, Y., 2014, Temperature-sensitive electrochemical recognition of tryptophan enantiomers based on $\beta$-cyclodextrin self-assembled on poly (L-glutamic acid), Anal. Chem., 86 (5), 2633-2639.

[27] Surikumaran, H., Mohamad, S., and Sarih, N.M., 2014, Molecularly imprinted polymer of methacrylic acid functionalised $\beta$-cyclodextrin for selective removal of 2,4-dichlorophenol, Int. J. Mol. Sci., 15 (4), 6111-6136.

[28] Ruela, A.L.M., Figueiredo, E.C., and Pereira, G.R., 2014, Molecularly imprinted polymers as nicotine transdermal delivery systems, Chem. Eng. J., 248, 1-8. 